\title{
Effect of EGF and AREG Treatment During Porcine in vitro Maturation on in vitro Developmental Potential of Preimplantation Embryos
}

\author{
Se-Heon Jeung, Yu-Byeol Jeon, Dibyendu Biswas, \\ Kyung-Chul Choi, Eui-Bae Jeung and Sang-Hwan Hyun \\ Department of Veterinary Medicine, College of Veterinary Medicine, \\ Chungbuk National University, 361-763 Cheongju, Chungbuk, Republic of Korea
}

\begin{abstract}
Porcine In Vitro Maturation (IVM) and In Vitro Fertilization (IVF) technique has been used and improved. However, polyspermic penetration, low rate of Blastocyst (BL) formation and poor quality of BLs are induced by imperfect nuclear and cytoplasmic maturation. It has been reported that Epidermal Growth Factor (EGF) is beneficial for oocyte maturation to improve the IVM system and Amphiregulin (AREG) is a growth factor containing an EGF-like domain. Consequently, the present study was performed to investigate whether during porcine IVM system EGF and/or AREG supplementation is profitable for improving oocyte maturation and embryo development. In Experiment 1, oocytes were maturated with EGF (15 ng $\mathrm{mL}^{-1}$ ) or AREG (15 ng mL $\mathrm{mL}^{-1}$ ) or combination of both and after $44 \mathrm{~h}$, oocytes were stained with Hoechst and metaphase II and development rate were evaluated. Without any growth factor served as a control. In Experiment 2 , maturated oocytes from the previous groups were fertilized with proven sperm and penetration rate after $10 \mathrm{~h}$ of post-insemination was evaluated. In Experiment 3 in vitro matured porcine oocytes were stained with fluorescein isothiocyanate-labeled peanut agglutinin and the distribution of Cortical Granules (CGs) was evaluated by laser confocal microscopy. In Experiment 1, the oocytes maturation rate were significantly higher in EGF, AREG or combined group (70.9 $\pm 15.5,75.8 \pm 9.8$ and $70.5 \pm 10.8 \%$, respectively) compared to control $(51.6 \pm 18.3 \%)$ but no significant difference among the treatments group. In Experiment 2 , there was no significance of sperm penetration rate among the groups however, polyspermy and sperm number per oocytes were decreased significantly $(\mathrm{p}<0.05)$ in combined group $(26.7 \pm 12.0$ and $1.35 \pm 0.2 \%$, respectively) compared with control (43.5 \pm 13.1 and 1.63 $\pm 0.3 \%$, respectively). In Experiment 3, BL formation rate were significantly $(\mathrm{p}<0.05)$ higher in combined group $(17.1 \pm 5.0 \%)$ compared with control and EGF group $(9.4 \pm 3.2$ and $13.1 \pm 4.6 \%$, respectively) but the TE cell number and total cell number were significantly higher in $(\mathrm{p}<0.05)$ combined group compared to control and other treatment group. In Experiment 3, the CG area was increased significantly $(\mathrm{p}<0.05)$ in all treatment groups compared with control group (11.1 $\pm 3.4,9.7 \pm 3.0$ and $10.4 \pm 2.8 \mathrm{vs} .4 .1 \pm 1.8 \%$, respectively). These results indicate that the addition of EGF and/or AREG to porcine IVM medium that enhances oocyte maturation and increases the total cell number. Combination of both growth factors also increases development rate and decreases polyspermy. Therefore, it is suggested that AREG can assist immature porcine oocytes to the metaphase II stage, enhance developmental potential in in vitro system and that there is due to synergistic effect of EGF and AREG during oocytes and embryonic development.
\end{abstract}

Key words: IVM, IVF, EGF, amphiregulin, cortical granule, polyspermy

\section{INTRODUCTION}

In mammal, preovulatory oocytes are maintained in a diplotene stage of meiotic prophase by an oocyte maturation inhibitor secreted from follicles (Tsafriri and Pomerantz, 1984). However, the preovulatory Luteinizing Hormone ( $\mathrm{LH}$ ) surge induces reentry into the first meiotic division of oocytes (Hsieh et al., 2007). The oocyte maturation represents that female gamete changes from a developmentally incapable cell to one with ability to fertilization and embryonic development. In vivo, the oocyte is exposed to Follicle-Stimulating Hormone (FSH), $\mathrm{LH}$, steroid, maturation-promoting factor, growth factors and other factors and these may interact to regulate the maturation of oocyte.

In vitro, the suitable medium and supplements can mature oocyte to be fertilizable. However, imperfect nuclear and cytoplasmic maturation can cause

Corresponding Author: Sang Hwan Hyun, Lab of Veterinary Embryology and Biotechnology, College of Veterinary Medicine, Chungbuk National University, 361-763 Cheongju, Chungbuk, Republic of Korea 
polyspermic fertilization and formation of poor quality Blastocysts (BLs) (Han et al., 1999) and many studies have experimented to decrease polyspermic fertilization and improve embryo development (Abeydeera and Day, 1997a, b). In pigs, porcine Follicular Fluid (pFF) (Naito et al., 1988), cysteine (Yoshida et al., 1992), insulin (Singh and Armstrong, 1997) and Epidermal Growth Factor (EGF) (Grupen et al., 1997; Abeydeera et al., 2000; Hong et al., 2004) can contribute to nuclear and cytoplasm maturation. Among the factors, EGF is reported beneficial on oocyte to improve In Vitro Maturation (IVM) system (Ding and Foxcroft, 1994; Grupen et al., 1997; Abeydeera et al., 1998). However, Tissue Culture Media (TCM)-199 supplemented with EGF is used on porcine oocyte maturation in many studies. The main positive effect of EGF is to stimulate the synthesis of intracellular Glutathione (GSH) (Abeydeera et al., 2000) and followed high concentration of intracellular GSH effects on embryo development, acts on the protein synthesis and amino acid transport and promotes male pronuclear formation (Whitaker and Knight, 2004).

It has been known that Amphiregulin (AREG) which is a member of EGF family and expresses in the luminal epithelium of mouse uterus (Das et al., 1995) and in ovarian epithelial cell that could affects cumulus expansion and oocyte maturation in human (Shoyab et al., 1989). However, it is believed that it could be involved to improve oocyte quality during oocyte maturation (Lee et al., 2009) but the role of AREG on oocytes yet to be clear. Consequently, the present study was performed to investigate whether TCM-199 supplemented with EGF and/or AREG is profitable for improving the oocyte maturation and development of porcine In Vitro Fertilization (IVF) embryos.

\section{MATERIALS AND METHODS}

Sampling of ovaries, aspiration and selection of oocytes: Slaughterhouse-derived porcine (mixed type-Yorkshire, Landrace and Duroc about 6 months old gilt) ovaries were carried to the laboratory in antibiotics (amoxicillin $20 \mathrm{mg} \mathrm{mL}^{-1}$ and clavulanic acid $4 \mathrm{mg} \mathrm{mL}^{-1}$ ) added $0.9 \%$ $\mathrm{NaCl}$ within $2 \mathrm{~h}$. Collected ovaries were washed (2 times) with $0.9 \% \mathrm{NaCl}$ and maintained at $39^{\circ} \mathrm{C}$. Oocytes were aspirated from 3-6 $\mathrm{mm}$ follicular size with 18 gauge needle attached to a $10 \mathrm{~mL}$ syringe and collected in a $15 \mathrm{~mL}$ conical centrifuge tubes for sedimentation. After $10 \mathrm{~min}$, supernatant fluid was removed and the conical tube was filled with tyrode lactate HEPESPolyvinylalcohol (TLH-PVA) up to 5-6 mL. Thereafter, the contents were poured in petri dish and oocytes which had homogenous ooplasm and intact culumus oophurus were selected for IVM.
In Vitro Maturation (IVM): Forty to fifty selected cumulus oocytes complexes were maturated in $500 \mu \mathrm{L}$ modified Tissue Culture Medium-199 (TCM-199; Invitrogen Corporation, Carlsbad, CA, USA) supplemented with EGF and AREG according to experimental design. First 20-22 h they were cultured with eCG $4 \mathrm{IU} \mathrm{mL}^{-1}$ (Intevet, Folligon) and hCG $4 \mathrm{IU} \mathrm{mL}^{-1}$ (Intervet, Chorulon) at $39.5^{\circ} \mathrm{C}, 5 \% \mathrm{CO}_{2}$. After $22 \mathrm{~h}$, oocytes were transferred to M199 without eCG/hCG at $39.5^{\circ} \mathrm{C}, 5 \% \mathrm{CO}_{2}$.

In Vitro Fertilization (IVF): Maturated oocytes were denuded by $0.1 \%$ hyaluronidase (Sigma, H-3506) and washed 3 times with TLH-PVA. Thereafter, 15 oocytes were transferred to $40 \mathrm{~mL}$ modified Tris-Buffered Medium (mTBM) drop covered with mineral oil. A straw of frozen boar semen was thawed at $39^{\circ} \mathrm{C}$ for $2 \mathrm{~min}$ in a water bath and washed in $10 \mathrm{~mL}$ Phosphate Buffered Saline (PBS) by centrifuging twice at $2000 \mathrm{rpm}$ for $2 \mathrm{~min}$. The sperm pellet was resuspended in $\mathrm{mTBM}$ that was pre-equilibrated for $18 \mathrm{~h}$ at $39^{\circ} \mathrm{C}$ under $5 \% \mathrm{CO}_{2}$. After appropriate dilution, $5 \mu \mathrm{L}$ of sperm suspension was added to a $40 \mathrm{~mL}$ drop of fertilization medium (mTBM) to give a final sperm concentration of $2 \times 10^{6}$ sperm $\mathrm{mL}^{-1}$. Gametes were cocultured for $6 \mathrm{~h}$ at $39^{\circ} \mathrm{C}$ in a humidified atmosphere of $5 \%$ $\mathrm{CO}_{2}$ and $95 \%$ air.

In Vitro Culture (IVC): After 6 h of fertilization, gametes were removed from the mTBM drops, washed 3 times in TLH-PVA and cultured in $30 \mu \mathrm{L}$ microdrops ( 10 gametes per drop) of North Carolina State University (NCSU-23) medium covered with mineral oil and incubated under $5 \% \mathrm{O}_{2}, 5 \% \mathrm{CO}_{2}$ and $90 \% \mathrm{~N}_{2}$ at $39.8^{\circ} \mathrm{C}$ for $168 \mathrm{~h}$. The cleavage rate and $\mathrm{BL}$ formation were evaluated under a stereomicroscope at 48 and $168 \mathrm{~h}$ after insemination, respectively.

Maturation rate check: After 40-42 h of IVM, denuded oocytes were washed TLH-PVA and fixed with $4 \%$ paraformaldehyde in PBS for $10 \mathrm{~min}$ and stained with Hoechst for $5 \mathrm{~min}$. Thereafter, oocytes were mounted and assessed by epifluorescence microscopy (Leica, DMI 4000B). Polar body and MII plate were considered as matured oocytes.

Penentration rate (polyspermy) check: About $10 \mathrm{~h}$ after fertilization the zygotes were washed with TLH-PVA and zona pellucida was removed by $0.5 \%$ protease by gentle pipetting. Thereafter, oocytes without zona pellucid were washed in TLH-PVA medium containing a solution of $0.1 \%$ formaldehyde and $0.01 \%$ PVA in PBS for $1 \mathrm{~min}$ and fixed in 1\% formaldehyde and $0.01 \%$ PVA in PBS for $10 \mathrm{~min}$ at room temperature. Fixed embryos were placed in a drop of mounting medium on slide and covered with a 
cover slide. The mounting medium consisted with $25 \%$ glycerol in PBS containing $2.5 \mathrm{mg} \mathrm{mL}^{-1}$ sodium azide and $2.5 \mu \mathrm{g} \mathrm{mL}{ }^{-1}$ Hoechst. After $5 \mathrm{~min}$, numbers of sperm head penetrating the zona pellucid, polyspermy were assessed by epifluorescence microscopy.

Assessment of the number of cells in BL: The qualities of BLs were assessed by differential staining of Inner Cell Mass (ICM) and the Trophectoderm (TE) cells according to Thouas et al. (2001) with little modifications. Briefly, TE cells of BLs at $168 \mathrm{~h}$ were stained with $0.1 \mathrm{mg} \mathrm{mL}^{-1}$ fluorochrome propidium iodide for $10 \mathrm{sec}$ after treatment with permeabilizing solution containing $2 \%(\mathrm{v} / \mathrm{v})$ Triton $\mathrm{X}-100$ ionic detergent. BLs was then incubated in a second solution containing $3 \mu \mathrm{g} \mathrm{mL} \mathrm{mL}^{-1}$ Hoechst in $100 \%$ ethanol at $4^{\circ} \mathrm{C}$ for $90 \mathrm{~min}$. After Hoechst stain, BLs were transferred to third solution containing $100 \%$ ethanol for $80 \mathrm{~min}$. Fixed and stained whole Bls were mounted and assessed for cell number using epifluorescence microscopy.

Cortical Granule (CG) stain and assessment: Methods of $\mathrm{CG}$ visualization were based on those described by Wang et al. (1998). After IVM, denuded oocytes were fixed by $3.7 \%$ paraformaldehyde in PBS. After $30 \mathrm{~min}$, oocytes were washed 3 times in PBS. After being treated for $5 \mathrm{~min}$ in PBS containing $0.5 \%$ Triton X-100, oocytes were washed 2 times. Oocytes were then cultured in $100 \mu \mathrm{g} \mathrm{mL} \mathrm{m}^{-1}$ fluorescein isothiocyanate-labeled peanut agglutinin (FITC-PNA, Sigma) in PBS for $30 \mathrm{~min}$ in a dark. After staining, the oocytes were washed in PBS. Confocal microscopy was used for assessment of CGs. Area of CGs was calculated by EZ-C1 (Gold Version 3.20 build 610) and total area of oocyte were divided to the area except CG of oocyte (Fig. 1).

Experimental designs: In Experiment 1, effects of AREG

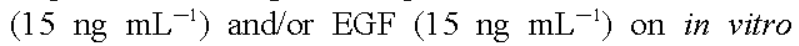
maturation of porcine oocytes were evaluated after 42-44 h of culture. Following IVM, oocytes were stained and with Hoechst and assessed by epifluorescence microscopy. In Experiment 2, sperm penetrations were checked in regards to different groups after $10 \mathrm{~h}$ of insemination. In Experiment 3 and 4, the in vitro developmental potential of porcine IVF embryos and areas of cortical granules were assessed after matured with AREG and/or EGF during IVM system.

Statistical analysis: All percentage data and data sets obtained from this study were expressed as mean \pm SD. Differences in developmental rate and cell numbers of the embryos between experimental groups were analyzed by
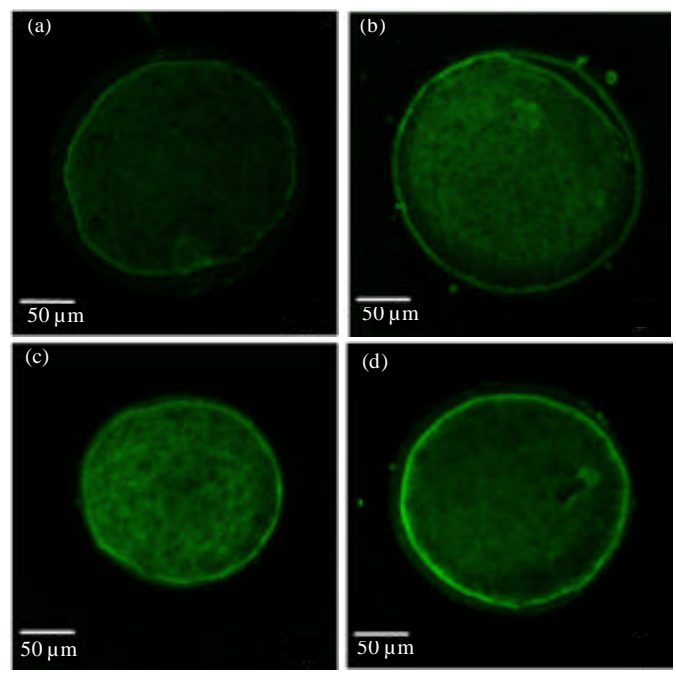

Fig. 1: Confocal microscopic images of CGs distribution in pig oocytes stained with FITC-PNA. A monolayer $\mathrm{CG}$ distribution under plasma membrane was observed in an oocyte after $44 \mathrm{~h}$ of culture. Green images represent CG staining; a) control; b) EGF $15 \mathrm{ng} \mathrm{mL}{ }^{-1}$; c) AREG $15 \mathrm{ng} \mathrm{mL}^{-1}$ and d) EGF $15 \mathrm{ng} \mathrm{mL}{ }^{-1}+$ AREG $15 \mathrm{ng} \mathrm{mL}^{-1}$

Duncan multiple range test using SPSS Version 17.0 for Windows (SPSS, Inc., Chicago, IL). Differences were considered to be significant if $\mathrm{p}<0.05$.

\section{RESULTS}

Experiment 1 (effect of EGF and/or AREG on in vitro maturation of oocytes): Metaphase II stage was significantly increased in EGF, AREG and EGF+AREG $(70.9 \pm 15.5,75.8 \pm 9.8$ and $70.5 \pm 10.8 \%$, respectively) compare to control $(51.6 \pm 18.3 \%)$ and it was also observed that metaphase I stage was significant decreased in groups of EGF, AREG and EGF+AREG $(24.3 \pm 9.9,20.0 \pm 8.6$ and $24.5 \pm 8.7 \%$ ) than the control group ( $40.4 \pm 13.1 \%)$. But there was no difference in the rates of GV and GVBD stage among the groups (Table 1).

\section{Experiment 2 (effect of EGF and/or AREG on sperm} penetration): Polyspermic penetration was significantly decreased in EGF+AREG group compare to control ( $26.6 \pm 12.0$ vs. $43.5 \pm 13.1 \%$, respectively). But there was no any significant difference in penetration rate among the treatment groups (Table 2). However, number of sperm penetrate per oocytes was significantly $(\mathrm{p}<0.05)$ lower in EGF+AREG combined group (1.35 \pm 0.2$)$ compared to control $(1.63 \pm 0.3)$. 
Table 1: Effect of EGF/AREG treatment during porcine in vitro maturation on nuclear maturation

\begin{tabular}{|c|c|c|c|c|c|}
\hline \multirow[b]{2}{*}{ Groups } & \multirow{2}{*}{$\begin{array}{l}\text { No. of oocytes } \\
\text { examined }\end{array}$} & \multicolumn{4}{|c|}{ No. (mean $\pm \mathrm{SD} \%$ ) } \\
\hline & & GV & GVBD & MI & MII \\
\hline Control & 188 & $4(2.1 \pm 2.7)$ & $11(5.9 \pm 6.6)$ & $76(40.4 \pm 13.1)^{a}$ & $97(51.6 \pm 18.3)^{\mathrm{a}}$ \\
\hline EGF $15 \mathrm{ng} \mathrm{mL}^{-1}$ & 189 & $0(0.0 \pm 0.0)$ & $9(4.8 \pm 6.5)$ & $46(24.3 \pm 9.90)^{b}$ & $134(70.9 \pm 15.5)^{b}$ \\
\hline AREG $15 \mathrm{ng} \mathrm{mL}^{-1}$ & 190 & $2(1.1 \pm 1.6)$ & $6(3.2 \pm 2.0)$ & $38(20.0 \pm 8.60)^{b}$ & $144(75.8 \pm 9.80)^{b}$ \\
\hline EGF $15 \mathrm{ng} \mathrm{mL}^{-1}+$ AREG $15 \mathrm{ng} \mathrm{mL}^{-1}$ & 200 & $5(2.5 \pm 2.9)$ & $5(2.5 \pm 5.0)$ & $49(24.5 \pm 8.70)^{b}$ & $141(70.5 \pm 10.8)^{b}$ \\
\hline
\end{tabular}

Table 2: Penetration and polyspermic fertilization rates of porcine oocytes cultured in TCM-199 supplemented with absence or presence of EGF and/or AREG

\begin{tabular}{|c|c|c|c|c|c|c|c|}
\hline \multirow[b]{2}{*}{ Groups } & \multirow{2}{*}{$\begin{array}{l}\text { No. of oocytes } \\
\text { examined }\end{array}$} & \multirow{2}{*}{$\begin{array}{l}\text { No. (mean } \pm \mathrm{SD} \% \text { ) } \\
\text { of penetrated }\end{array}$} & \multirow{2}{*}{$\begin{array}{l}\text { No. (mean } \pm \mathrm{SD} \%) \\
\text { of polyspermy }\end{array}$} & \multicolumn{3}{|c|}{ No. (mean $\pm \mathrm{SD} \%$ ) of Pns } & \multirow{2}{*}{$\begin{array}{c}\text { No. (mean } \pm \mathrm{SD} \%) \\
\text { of spermatozoa } \\
\text { in penetrated oocyte }\end{array}$} \\
\hline & & & & $2 \mathrm{PN}$ & $3 \mathrm{PN}$ & $4 \mathrm{PN}$ & \\
\hline Control & 232 & $161(69.4 \pm 7.30)$ & $70(43.5 \pm 13.1)^{a}$ & $91(56.5 \pm 13.1)^{a}$ & $39(24.2 \pm 9.60)$ & $31(19.3 \pm 14.1)^{\mathrm{a}}$ & $1.63 \pm 0.3^{\mathrm{a}}$ \\
\hline EGF $15 \mathrm{ng} \mathrm{mL}^{-1}$ & 242 & $167(69.0 \pm 10.3)$ & $54(32.3 \pm 12.1)^{\mathrm{a}, \mathrm{b}}$ & $113(67.7 \pm 12.1)^{\mathrm{a}, \mathrm{b}}$ & $42(25.2 \pm 15.6)$ & $12(7.2 \pm 5.70)^{b}$ & $1.40 \pm 0.1^{\mathrm{a}, \mathrm{b}}$ \\
\hline AREG $15 \mathrm{ng} \mathrm{mL}^{-1}$ & 248 & $162(65.3 \pm 8.50)$ & $48(29.6 \pm 12.1)^{\mathrm{a}, \mathrm{b}}$ & $114(70.4 \pm 12.1)^{\mathrm{a}, \mathrm{b}}$ & $30(18.5 \pm 11.3)$ & $18(11.1 \pm 6.80)^{\mathrm{a}, \mathrm{b}}$ & $1.41 \pm 0.2^{\mathrm{a}, \mathrm{b}}$ \\
\hline $\begin{array}{l}\text { EGF } 15 \mathrm{ng} \mathrm{mL}^{-1}+ \\
\text { AREG } 15 \mathrm{ng} \mathrm{mL}^{-1}\end{array}$ & 231 & $146(63.2 \pm 8.60)$ & $39(26.7 \pm 12.0)^{b}$ & $107(73.3 \pm 12.0)^{b}$ & $27(18.5 \pm 9.60)$ & $12(8.2 \pm 6.00)^{b}$ & $1.35 \pm 0.2^{b}$ \\
\hline
\end{tabular}

Within the same column, values with different superscripts letters (a and $b$ ) were different $(p<0.05)$. PN: Pronucleus

Table 3: Effects of EGF/AREG treatment during porcine IVM on preimplantation embry onic development after in vitro fertilization

\begin{tabular}{|c|c|c|c|c|c|c|c|}
\hline \multirow[b]{3}{*}{ Groups } & \multirow{3}{*}{$\begin{array}{l}\text { No. of oocytes } \\
\text { examined }\end{array}$} & \multicolumn{2}{|l|}{ Embryo development } & \multirow{3}{*}{$\begin{array}{l}\text { No. of blastocysts } \\
\text { evaluated }\end{array}$} & \multirow{2}{*}{\multicolumn{3}{|c|}{ Cell number $($ mean \pm SD) }} \\
\hline & & \multirow{2}{*}{$\begin{array}{l}\text { No. (mean } \pm \mathrm{SD} \%)^{*} \\
\text { of } \geq 2 \text { cells }\end{array}$} & \multirow{2}{*}{$\begin{array}{l}\text { No. (mean } \pm \text { SD } \%)^{*} \\
\text { of blastocysts }\end{array}$} & & & & \\
\hline & & & & & ICM & $\mathrm{TE}$ & Total cells \\
\hline Control & 701 & $394(56.2 \pm 12.6)$ & $66(9.4 \pm 3.2)^{\mathrm{a}}$ & 18 & $11.2 \pm 2.2$ & $45.2 \pm 24.6^{a}$ & $56.3 \pm 25.5^{\mathrm{a}}$ \\
\hline EGF $15 \mathrm{ng} \mathrm{mL}^{-1}$ & 709 & $397(56.0 \pm 14.9)$ & $93(13.1 \pm 4.6)^{\mathrm{a}, \mathrm{b}}$ & 19 & $11.8 \pm 2.7$ & $69.6 \pm 31.0^{b}$ & $81.4 \pm 32.0^{b}$ \\
\hline AREG $15 \mathrm{ng} \mathrm{mL}^{-1}$ & 711 & $393(55.3 \pm 11.4)$ & $98(13.8 \pm 6.0)^{b, c}$ & 16 & $11.7 \pm 3.4$ & $68.0 \pm 27.4^{b}$ & $79.7 \pm 27.3^{b}$ \\
\hline $\begin{array}{l}\text { EGF } 15 \mathrm{ng} \mathrm{mL}^{-1}+ \\
\text { AREG } 15 \mathrm{ng} \mathrm{mL}^{-1}\end{array}$ & 708 & $402(56.8 \pm 11.5)$ & $121(17.1 \pm 5.0)^{c}$ & 19 & $11.6 \pm 3.8$ & $68.7 \pm 25.6^{b}$ & $80.3 \pm 28.6^{b}$ \\
\hline
\end{tabular}

Within the same column, values with different superscripts letters (a-c) were different $(\mathrm{p}<0.05)$. ICM: Inner Cell Mass; TE: Trophectoderm; ${ }^{*}$ Percentage of the number of oocytes cultured

Table 4: Area of cortical granule in equator of oocytes maturated in medium for $44 \mathrm{~h}$

\begin{tabular}{lc}
\hline Groups & $\begin{array}{c}\text { Area fraction of cortical } \\
\text { granules (mean+SD\%) }\end{array}$ \\
\hline Control & $4.1 \pm 1.8^{\mathrm{a}}$ \\
EGF 15 $\mathrm{ng} \mathrm{mL}^{-1}$ & $11.1 \pm 3.4^{\mathrm{b}}$ \\
AREG 15 ng mL & $9.7 \pm 3.0^{b}$ \\
EGF 15 $\mathrm{ng} \mathrm{mL}^{-1}+$ AREG 15 ng mL & $10.4 \pm 2.8^{\mathrm{b}}$ \\
\hline Within the same column, values with different superscripts letters (a and b) & \\
were different $(\mathrm{p}<0.05)$ &
\end{tabular}

Experiment 3 (effects of EGF and/or AREG on in vitro developmental potential of porcine in vitro fertilized embryos): There was no significant difference of cleavage rate among the groups.

However, BL developmental rates in the EGF+AREG group $(17.1 \pm 5.0 \%)$ were significantly increased compared with control, AREG and EGF group (9.4 \pm 3.2 and $13.1 \pm 4.6 \%$ ). Total cell number as well as TE cell number was significantly increased in all treatment groups compared to control (Table 3).

Experiment 4 (effects of EGF and/or AREG on area of CG distribution): Area of cortical granule distribution was significantly increased in all treatment groups compared to control but no any significant difference among the treatment groups (Table 4).

\section{DISCUSSION}

AREG is a member of the EGF family and its role can be inferred from the study of EGF. Previously it was reported that ampherulin could influence trophoectoderm cell number of porcine in vitro IVF and parthenogenetic embryos and also this protein was detected in cytoplasm (Lee et al., 2009). The exact role of AREG was not elucidated but it could be involved to improve oocyte quality. It was reported that EGFs promote emission of first polar bodies (Abeydeera, 2002) and the results have shown a similar result of porcine IVF embryos. An influence to nuclear maturity with the help of exogenous AREG which is EGF-like peptide and AREG may operate like EGF. Conti et al. (2006) are appearing about AREG roles. However, AREG receptor existed but still separately operate to that place to EGF receptor where they operated and the effect should have been born, reveals and support after combined operating which is not but the process which happens is thought being similar.

Cytoplasmic maturity is important for embryonic developmental during in vitro. Cytoplasmic organelle are redistributed and migrated during meiosis towards periphery and the CG density and cortical localization in 
matured oocytes are important markers for cytoplasmic maturation (Cran and Esper, 1990; Liuet al. 2005). CGs are a specialized group of membrane-bound secretory granules composed of specialized enzymes and glycoproteins that are exquisitely localized near their site of release at non-penetrated oocytes (Gulyas, 1980; Dandekar and Talbot, 1992) and close to their site of action such as the zona pellucida. Thousands of CGs are situated within $2 \mu \mathrm{m}$ of the plasma membrane of the mature egg and few are detected in subcortical regions (Ducibella et al., 1990). In mammals, the release of CGs by exocytosis after gamete membrane fusion appears to block polyspermy by changing the properties of the $\mathrm{ZP}$ and forming a new envelope like structure in the perivitelline space (Long et al., 1994). In order to evaluate the ooplasmic maturity, the CG areas were stained with FITC-PNA and observed with confocal microscopy. In matured oocyte the $\mathrm{CG}$ are dispersed uniformly to periphery of the cytoplasm (Li et al., 2003). To evaluate CG area, researchers used the method to divide the bulk of the ovum whole with CG area and the fact that CG area is not governed in compliance with an oocyte size. Researchers observed CG area was relatively increased in EGF/or AREG or in both treated oocytes than controls. In the result showed that sperm penetration was not any significant different among the groups, monospermic penetration was significantly higher in EGF and AREG group compared to controls and also the polyspermic penetration was significantly lower in EGF and AREG group compared to control. This result indicated that addition of AREG combination with EGF have some beneficial effects during oocytes maturation. During sperm penetration CG prevents polyspermy by cortical reaction and CG exocytosis (Miyazaki et al., 1993). Cortical reaction is thought to play a major rule to secrete materials which makes zona hardening that reduced polyspermy during the conventional IVF system (Miyazaki et al., 1993). In the study indicated that addition of AREG along with EGF prevents sperm penetration per oocyte significantly compared to controls.

In vitro blastocyst formation is dependent on oocytes cytoplasmic quality during oocyte maturation. During in vitro maturation oocyte-synthesized materials are involved to prepare oocyte cytoplasm for proper fertilization. Normal fertilization would help to proper embryos development. In the study showed that addition of AREG along with EGF during in vitro maturation of porcine oocytes significantly increased embryonic developmental potential and the total cell number per blastocyst of in vitro fertilized embryos compared with the control group and this is could be due to synergy effect of EGF and AREG to the embryos during oocyte maturation. During in vitro maturation proper $\mathrm{CG}$ distributions also important for proper fertilization and subsequent embryo development. Improper CG distribution could lead to abnormal sperm penetration and reduced embryos development and sometime lethal to the oocytes (Hunter, 1991). The oocytes which were treated with EGF or AREG alone during IVM that contribute to increase BL formation and as well the trophectoderm cell number and those may result of nuclear and cytoplasmic maturation. Furthermore, the increased trophectoderm could help to placentation and researchers hypothesized that AREG could affect the SCNT embryo implantation.

\section{CONCLUSION}

In this study, the addition of exogenous AREG during IVM period could help nuclear and cytoplasmic maturation of porcine oocytes. Moreover, increased BL formation and cell number were observed in IVF with AREG treated oocytes.

\section{ACKNOWLEDGEMENT}

This research was supported by a grant from Next-Generation BioGreen 21 program (\#PJ008121012011), Rural Development Administration, Republic of Korea.

\section{REFERENCES}

Abeydeera, L.R. and B.N. Day, 1997a. In vitro penetration of pig oocytes in a modified Tris-buffered medium: Effect of BSA, caffeine and calcium. Theriogenology, 48: $537-544$.

Abeydeera, L.R. and B.N. Day, 1997b. Fertilization and subsequent development in vitro of pig oocytes inseminated in a modified tris-buffered medium with frozen-thawed ejaculated spermatozoa. Biol. Reprod., 57: 729-734.

Abeydeera, L.R., 2002. In vitro production of embryos in swine. Theriogenology, 57: 256-273.

Abeydeera, L.R., W.H. Wang, T.C. Cantley, A. Rieke, C.N. Murphy, R.S. Prather and B.N. Day, 2000. Development and viability of pig oocytes matured in a protein-free medium containing epidermal growth factor. Theriogenology, 54: 787-797.

Abeydeera, L.R., W.H. Wang, T.C. Cantley, A. Rieke, R.S. Prather and B.N. Day, 1998. Presence of epidermal growth factor during in vitro maturation of pig oocytes and embryo culture can modulate blastocyst development after in vitro fertilization. Mol. Reprod. Dev., 51: 395-401. 
Conti, M., M. Hsieh, J.Y. Park and Y.Q. Su, 2006. Role of the epidermal growth factor network in ovarian follicles. Mol. Endocrinol., 20: 715-723.

Cran, D.G. and C.R. Esper, 1990. Cortical granules and the cortical reaction in mammals. J. Reprod. Fertil. Suppl., 42: 177-188.

Dandekar, P. and P. Talbot, 1992. Perivitelline space of mammalian oocytes: extacellular matrix of unfertilized oocytes and formation of cortical granule envelope following fertilization. Mol. Reprod. Dev., 31: 135-143.

Das, S.K., I. Chakraborty, B.C. Paria, X.N. Wang, G. Plowman and S.K. Dey, 1995. Amphiregulin is an implantation-specific and progesteroneregulated gene in the mouse uterus. Mol. Endocrinol., 9: 691-705.

Ding, J. and G.R. Foxcroft, 1994. Epidermal growth factor enhances oocyte maturation in pigs. Mol. Reprod. Dev., 39: 30-40.

Ducibella, T., S. Kurasawa, S. Rangarajan, G.S. Korf and R.M. Schultz, 1990. Precocious loss of cortical granules during mouse oocyte meiotic maturation and correlation with an egg-induced modification of the zona pellucid. Dev. Biol., 137: 46-55.

Grupen, C.G., H. Nagashima and M.B. Nottle, 1997. Role of epidermal growth factor and insulin-like growth factor-I on porcine oocyte maturation and embryonic development in vitro. Reprod. Fertile. Dev., 9: 571-575.

Gulyas, B.J., 1980. Cortical granules of mammalian eggs. Int. Rev. Cytol., 63: 357-392.

Han, Y.M., W.H. Wang, L.R. Abeydeera, A.L. Petersen and J.H. Kim et al., 1999. Pronuclear location before the first cell division determines ploidy of polyspermic pig embryos. Biol. Reprod., 61: 1340-1346.

Hong, J.Y., H.Y. Yong, B.C. Lee, W.S. Hwang, J.M. Lim and E.S. Lee, 2004. Effects of amino acids on maturation, fertilization and embryo development of pig follicular oocytes in two IVM media. Theriogenology, 62: 1473-1482.

Hsieh, M., D. Lee, S. Panigone, K. Horner and R. Chen et al., 2007. Luteinizing hormone-dependent activation of the epidermal growth factor network is essential for ovulation. Mol. Cell. Biol., 27: 1914-1924.

Hunter, R.H., 1991. Oviduct functions in pigs, with particular reference to the pathological condition of polyspermy. Mol. Reprod. Dev., 29: 385-391.

Lee, J.H., E. Lee, D. Biswas, C.S. Jeung, G.S. Lee, S.H. Hyun and E.B. Jeung, 2009. Amphiregulin promotes the proliferation of trophoblast cells during preimplantation development of porcine embryos. Theriogenology, 72: 1023-1031.
Li, Y.H., W. Ma, M. Li, Y. Hou, L.H. Jiao and W.H. Wang, 2003. Reduced polyspermic penetration in porcine oocytes inseminated in a new In vitro fertilization (IVF) system: Straw IVF. Biol. Reprod., 69: 1580-1585.

Liu, X.Y., S.F. Mal, D.Q. Miao, D.J. Liu, S. Bao and J.H. Tan, 2005. Cortical granules behave differently in mouse oocytes matured under different conditions. Hum. Reprod., 20: 3402-3413.

Long, C.R., P. Damiani, C. Pinto-Correia, R.A. MacLean, R.T. Duby and J.M. Robl, 1994. Morphology and subsequent development in culture of bovine oocytes matured in vitro under various conditions of fertilization. J. Reprod. Fertil., 102: 361-369.

Miyazaki, S., M. Shirakawa, K. Nakada and Y. Honda, 1993. Essential role of the inositol 1,4,5 trisphasphate receptor/Ca2+ release channel in $\mathrm{Ca} 2+$ waves and $\mathrm{Ca} 2+$ oscillations at fertilization of mammalian eggs. Dev. Biol., 158: 62-78.

Naito, K., Y. Fukuda and Y. Toyoda, 1988. Effects of porcine follicular fluid on male pronucleus formation in porcine oocytes matured in vitro. Gamete Res., 21: 289-295.

Shoyab, M., G.D. Plowman, V.L. McDonald, J.G. Bradley and G.J. Todaro. 1989. Structure and function of human amphiregulin: A member of the epidermal growth factor family. Science, 243: 1074-1076.

Singh, B. and D.T. Armstrong, 1997. Insulin-like growth factor-1, a component of serum that enables porcine cumulus cells to expand in response to follicle-stimulating hormone in vitro. Biol. Reprod, 56: $1370-1375$.

Thouas, G.A., N.A. Korfiatis, A.J. French, G.M. Jones and A.O. Trounson, 2001. Simplified technique for differential staining of inner cell mass and trophectoderm cells of mouse and bovine blastocysts. Rep. Biomed. Online, 3: 25-29.

Tsafriri, A. and S.H. Pomerantz, 1984. Regulation of the development of meiotic competence and of the resumption of oocyte maturation in the rat. Sympo. Soc. Exp. Biol., 38: 25-43.

Wang, W.H., L.R. Abeydeera, R.S. Prather and B.N. Day, 1998. Morphologic comparison of ovulated and in vitro matured porcine oocytes, with particular reference to polyspermy after in vitro fertilization. Mol. Reprod. Dev., 49: 308-316.

Whitaker, B.D. and J.W. Knight, 2004. Exogenous gammaglutamyl cycle compounds supplemented to in vitro maturation medium influence in vitro fertilization, culture and viability parameters of porcine oocytes and embryos. Theriogenology, 62: 311-322.

Yoshida, M., K. Ishigaki and V.G. Pursel., 1992. Effect of maturation media on male pronucleus formation in pig oocytes matured in vitro. Mol. Reprod. Dev., 31: 68-71. 